\title{
Racial/ethnic differences in inpatient mortality and use of institutional postacute care following subarachnoid hemorrhage
}

\author{
Clinical article
}

\author{
Blessing N. R. Jaja, M.B.B.S., M.Sc., ${ }^{1,3,4}$ Gustavo SAPosnik, M.D., M.Sc., F.R.C.P.C., ${ }^{2-4}$ \\ Rosane Nisenbaum, Ph.D., ${ }^{3,5}$ Benjamin W. Y. Lo, M.D., M.Sc., F.R.C.S.C., ${ }^{1,3}$ \\ Tom A. Schweizer, Ph.D., ${ }^{1,3,4}$ Kevin E. Thorpe, M.Math., Ph.D., ${ }^{3,5}$ \\ and R. Loch Macdonald, M.D., Ph.D., F.R.C.S..$^{1,3,4}$
}

${ }^{1}$ Division of Neurosurgery, ${ }^{2}$ Division of Neurology, and ${ }^{3} \mathrm{Li}$ Ka Shing Knowledge Institute, St. Michael's Hospital, Toronto; and ${ }^{4}$ Institute of Medical Science, and ${ }^{5}$ Dalla Lana School of Public Health, University of Toronto, Ontario, Canada

\begin{abstract}
Object. The goal of this study was to determine racial/ethnic differences in inpatient mortality rates and the use of institutional postacute care following subarachnoid hemorrhage (SAH) in the US.

Methods. A cross-sectional study of hospital discharges for SAH was conducted using the Nationwide Inpatient Sample for the years 2005-2010. Discharges with a principal diagnosis of SAH were identified and abstracted using the appropriate ICD-9-CM diagnostic code. Racial/ethnic groups were defined as white, black, Hispanic, Asian/ Pacific Islander (API), and American Indian. Multinomial logistic regression analyses were performed comparing racial/ethnic groups with respect to the primary outcome of risk of in-hospital mortality and the secondary outcome of likelihood of discharge to institutional care.

Results. During the study period, 31,631 discharges were related to SAH. Race/ethnicity was a significant predictor of death $(\mathrm{p}=0.003)$ and discharge to institutional care $(\mathrm{p} \leq 0.001)$. In the adjusted analysis, compared with white patients, API patients were at higher risk of death (OR 1.34,95\% CI 1.13-1.59) and Hispanic patients were at lower risk of death (OR 0.84, 95\% CI 0.72-0.97). The likelihood of discharge to institutional care was statistically similar between white, Hispanic, API, and Native American patients. Black patients were more likely to be discharged to institutional care compared with white patients (OR 1.27,95\% CI 1.14-1.40), but were similar to white patients in the risk of death.

Conclusions. Significant racial/ethnic differences are present in the risk of inpatient mortality and discharge to institutional care among patients with SAH in the US. Outcome is likely to be poor among API patients and best among Hispanic patients compared with other groups.
\end{abstract}

(http://thejns.org/doi/abs/10.3171/2013.7.JNS13544)

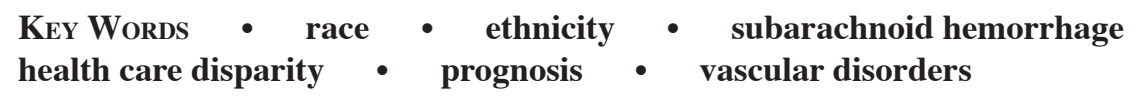

$\mathrm{S}$ UBARACHNOID hemorrhage (SAH) causes disproportionately higher rates of death and disability compared with other stroke subtypes. ${ }^{10}$ Epidemiological studies have demonstrated racial/ethnic differences in SAH incidence and mortality in the US. African-Americans, ${ }^{1,4,14-16,24}$ Asian/Pacific Islanders (APIs), ${ }^{1,21,24}$ and Hispanics ${ }^{1,6,8,16,24}$ have been shown to have higher incidences of and mortality rates from SAH compared with the white population. However, only a few studies have examined differences in outcomes among racial/ethnic

Abbreviations used in this paper: API = Asian/Pacific Islander; $\mathrm{CCI}=$ Charlson Comorbidity Index; NIS = Nationwide Inpatient Sample; $\mathrm{SAH}=$ subarachnoid hemorrhage. groups, while simultaneously accounting for factors that could potentially confound the race/ethnicity association with mortality. These studies have done so using patients participating in trials ${ }^{23}$ or patients in a small geographic cohort. 9,30

Furthermore, the study populations were more commonly recruited prior to significant paradigm changes in treatment practice, which has significantly impacted case fatality. Moreover, these studies have reported conflicting results. For instance, one post hoc analysis predominantly compared African-Americans to Caucasians who were re-

This article contains some figures that are displayed in color online but in black-and-white in the print edition. 
cruited into a large clinical trial between 1991 and 1997 and did not find any significant race/ethnic differences in 3 -month functional outcome. ${ }^{23}$ Another study based on the New York database of hospital discharges in 2003 reported that white patients in New York with SAH had better functional outcomes than nonwhite patients. ${ }^{30}$ It is presently unknown whether the use of institutional care among survivors of SAH differs across racial/ethnic groups. This study was therefore conducted to determine first whether racial/ ethnic groups differ in the risk of in-hospital mortality, and second whether racial/ethnic differences are present in the use of institutional postacute care following hospitalization for SAH.

\section{Methods}

\section{Patient Population}

The patient sample for this study was obtained from the Nationwide Inpatient Sample (NIS), Healthcare Cost and Utilization Project (HCUP), Agency for Healthcare Research and Quality, Rockville, Maryland. This database archives nationally representative data on inpatient stays at acute-care hospitals in the US and contains relevant demographic, diagnostic, procedure, and hospital information. We used data for the years 2005-2010 to analyze a cohort that would be most reflective of current treatment practices in SAH. Patients with SAH were identified using the appropriate ICD-9-CM diagnostic code (430) related to the principal diagnosis. To minimize including patients who may have traumatic SAH, the abstracted data set was further screened for secondary diagnoses related to head trauma (ICD-9-CM codes $800.0-801.9,803.0-804.9,850.0-854.1$, or 873.0-873.9). The study was approved by the research ethics board at St. Michael's Hospital.

\section{Variables Analyzed}

The independent variable was patient self-identified race/ethnicity, categorized in the NIS as white, black, Hispanic, API, Native American, or other. A number of covariates that could help explain or confound the effect of race/ethnicity on the outcomes of interest were accounted for in the analysis. These were patient age; sex; neighborhood median income according to patient zip code (expressed in quartiles - a measure of socioeconomic status at the community level); insurance status (categorized as Medicare, Medicaid, private including health maintenance organization [HMO], self-pay, or no charges); admission type (elective, urgent, or emergency); hospital region (Northeast, Midwest, South, or West); bed size (small, medium, or large); and hospital teaching status (nonteaching or teaching). To account for the effect of comorbid conditions, we computed each patient's Charlson Comorbidity Index (CCI) score according to the modification proposed by Deyo et al.; ${ }^{7}$ this is a weighted summary score based on the presence or absence of 17 medical conditions. We further categorized CCI into 4 groups, including CCIs of $1,2,3$, or $\geq 4$. The primary outcome was in-hospital mortality, whereas the secondary outcome was discharge to institutional care (defined as transfer to a short-term hospital); other transfer (including skilled nursing facility, intermediate care, and another type of facility); and home health care.

\section{Handling of Missing Data}

The proportion of missing data was less than $0.5 \%$ for most variables except for admission type (23.8\%), neighborhood median income quartile $(2.4 \%)$, and race (23.9\%). We set admission type to "emergency" if admission source was the emergency room; to "urgent" if admission source was from another hospital, including admissions from long-term facilities; and to "routine" if admission source was coded as "routine" in the NIS. This technique has been used previously. ${ }^{12}$ Multiple imputation was performed for all missing values of neighborhood income and race by using chained equations to generate 20 imputed data sets for analysis. ${ }^{27}$ The imputation model consisted of our predictor variable, explanatory variables, and outcome variable as well as weighting for discharge and hospital data provided for variance estimation.

\section{Statistical Analysis}

Patient demographic and clinical and hospital characteristics were summarized according to race/ethnicity by using descriptive statistics, with continuous variables expressed as the mean \pm SD and categorical variables expressed as frequencies (percentage). Differences among racial/ethnic groups for categorical variables were tested with a Mantel-Haenszel chi-square test, and for continuous variables differences were tested using ANOVA. The associations between race/ethnicity and patient discharge disposition were examined by fitting multinomial logistic regression models, adjusting for the aforementioned explanatory variables. The baseline outcome was routine discharge or discharged alive, destination unknown. In all analyses we accounted for the single-stage stratified cluster sampling design of the NIS by applying weighting for the discharge and hospital data provided in the NIS for accurate variance estimation, by using the Stata "svyset" suite of commands. This also allowed for extrapolation of results to the entire US population.

The level of statistical significance was set at $p \leq$ 0.05 . All analyses were repeated using complete cases only and gave similar results. All data analyses were performed with Stata version 12.1 (Stata Corp.).

\section{Results}

During the study period, 31,631 discharges were recorded in the NIS for SAH. Table 1 shows baseline characteristics of the study cohort by race/ethnicity. White and API patients were significantly older than patients in other ethnic groups $(\mathrm{p} \leq 0.001)$. Patients in the Hispanic group were less likely to be female compared with other groups. Black patients were more likely to live in lowincome neighborhoods, whereas API patients were more likely to live in high-income neighborhoods. The crude in-hospital mortality rate was $22 \%$, and the proportion of patients discharged to institutional care was $42 \%$.

In multivariable analyses, race/ethnicity was a signif- 
Racial/ethnic differences in mortality rates in patients with SAH

TABLE 1: Descriptive statistics of demographic, clinical, hospital, and outcome variables by race/ethnicity*

\begin{tabular}{|c|c|c|c|c|c|c|}
\hline Variable & White & Black & Hispanic & API & Native American/Other & Total \\
\hline no. of patients & 15,376 & 3,412 & 3,133 & 1,098 & 1,069 & 24,088 \\
\hline age† & $60.27 \pm 16.57$ & $53.00 \pm 15.42$ & $52.46 \pm 17.15$ & $59.80 \pm 17.79$ & $54.85 \pm 17.19$ & $57.96 \pm 16.9$ \\
\hline female sex & $9,489(62)$ & $2,227(65)$ & $1,822(58)$ & $717(65)$ & $634(59)$ & $14,899(62)$ \\
\hline \multicolumn{7}{|l|}{ income quartile } \\
\hline Q1 (lowest) & $3,336(22)$ & $1,623(49)$ & $1,077(36)$ & $125(12)$ & $234(23)$ & $6,395(27)$ \\
\hline Q2 & $4,034(27)$ & $716(22)$ & $743(25)$ & $189(18)$ & $271(27)$ & $5,953(25)$ \\
\hline Q3 & $3,752(25)$ & $556(17)$ & $690(23)$ & $257(24)$ & $239(24)$ & $5,494(24)$ \\
\hline Q4 (highest) & $3,886(26)$ & 407 (12) & $527(17)$ & $503(47)$ & $267(26)$ & $5,590(24)$ \\
\hline \multicolumn{7}{|l|}{ insurance status } \\
\hline Medicare & $5,935(39)$ & $865(25)$ & $666(21)$ & 347 (32) & $290(27)$ & $8,103(34)$ \\
\hline Medicaid & $1,220(8)$ & $672(20)$ & $770(25)$ & $151(14)$ & $185(17)$ & 2,998 (12) \\
\hline private/HMO & $6,437(42)$ & $1,199(35)$ & $949(30)$ & $458(42)$ & $413(39)$ & $9,456(39)$ \\
\hline self-pay & $1,140(7)$ & $443(13)$ & 444 (14) & $90(8)$ & $121(11)$ & $2,238(9)$ \\
\hline no charge/other & $599(4)$ & $215(6)$ & $301(10)$ & $52(4)$ & $56(5)$ & $1,223(5)$ \\
\hline \multicolumn{7}{|l|}{ admission type } \\
\hline emergency & $10,400(68)$ & $2,584(76)$ & $2,098(67)$ & $744(68)$ & $690(65)$ & $16,516(69)$ \\
\hline urgent & $3,534(23)$ & $557(16)$ & $629(20)$ & 205 (19) & $273(25)$ & $5,198(22)$ \\
\hline elective & $1,275(8)$ & $239(7)$ & $389(13)$ & $147(13)$ & $104(10)$ & $2,154(9)$ \\
\hline \multicolumn{7}{|l|}{ bed size } \\
\hline small & $854(6)$ & $126(4)$ & $179(6)$ & $86(8)$ & $60(6)$ & $1,305(5)$ \\
\hline medium & $2,856(19)$ & $656(20)$ & 406 (13) & $188(17)$ & $158(15)$ & $4,264(18)$ \\
\hline large & $11,518(75)$ & $2,568(76)$ & $2,541(81)$ & $820(75)$ & 838 (79) & $18,285(76)$ \\
\hline \multicolumn{7}{|l|}{ teaching status } \\
\hline nonteaching & $4,279(28)$ & $601(18)$ & $835(27)$ & $285(26)$ & $221(21)$ & $6,220(26)$ \\
\hline teaching & 10,950 (72) & $2,749(82)$ & $2,291(73)$ & 809 (74) & $835(79)$ & $17,634(74)$ \\
\hline \multicolumn{7}{|l|}{ region } \\
\hline Northeast & $3,494(23)$ & 760 (22) & $438(14)$ & $167(15)$ & $287(27)$ & $5,146(21)$ \\
\hline Midwest & $2,458(16)$ & $451(13)$ & $84(3)$ & 37 (3) & $154(14)$ & $3,184(13)$ \\
\hline South & $5,940(39)$ & $1,826(53.5)$ & $1,139(36)$ & $164(15)$ & $329(31)$ & $9,398(39)$ \\
\hline West & $3,484(22)$ & $375(11)$ & $1,472(47)$ & $730(66)$ & $299(28)$ & $6,360(26)$ \\
\hline \multicolumn{7}{|l|}{$\mathrm{CCl}$ score } \\
\hline 1 & $9,013(59)$ & $1,960(57)$ & $1,891(60)$ & $646(59)$ & 669 (62) & $14,179(59)$ \\
\hline 2 & $3,136(20)$ & $692(20)$ & $592(19)$ & $225(20)$ & $203(19)$ & $4,848(20)$ \\
\hline 3 & $1,964(13)$ & 409 (12) & 399 (13) & $139(13)$ & $116(11)$ & 3,027 (13) \\
\hline$\geq 4$ & $1,263(8)$ & $351(10)$ & $251(8)$ & $88(8)$ & $81(7)$ & $2,034(8)$ \\
\hline \multicolumn{7}{|l|}{ discharge status } \\
\hline in-hospital death & $3,530(23)$ & $686(20)$ & $575(18)$ & $294(27)$ & $231(22)$ & $5,316(22)$ \\
\hline institutional care & $6,526(42)$ & $1,528(45)$ & $1,213(39)$ & $465(42)$ & $460(43)$ & $10,192(42)$ \\
\hline routine discharge & $5,307(35)$ & $1,193(35)$ & $1,344(43)$ & $339(31)$ & $377(35)$ & $8,560(36)$ \\
\hline
\end{tabular}

* The total number of patients $(24,088)$ includes those for whom data are completely available for race/ethnicity. The denominators for each factor vary because of missing data. Numbers in parentheses represent percentages. $\mathrm{HMO}=$ health maintenance organization.

$\dagger$ Age is expressed as the mean \pm SD.

icant predictor of in-hospital mortality $(\mathrm{p}=0.003)$ and of discharge to institutional care $(\mathrm{p} \leq 0.001)$. Black patients were similar to white patients in the risk of in-hospital mortality (OR $1.04,95 \%$ CI $0.93-1.16$ ), but were more likely to be discharged to postacute institutional care than white patients (OR 1.27, 95\% CI 1.14-1.40) (Table 2 ). Hispanic patients were at significantly lower risk of in-hospital mortality than were white patients (OR 0.84, 95\% CI 0.72-0.97); however, both groups were statistically similar in likelihood of discharge to institutional care (OR 0.98, 95\% CI 0.87-1.09). Compared with white patients, API patients were at higher risk of death (OR $1.34,95 \%$ CI 1.13-1.59) and in greater need of institutional care (OR 1.17, 95\% CI 0.99-1.37). Similarly, Native 
TABLE 2: Results of multivariable analysis for in-hospital mortality and discharge to institutional care*

\begin{tabular}{|c|c|c|}
\hline Variable & $\begin{array}{l}\text { In-Hospital Mortality } \\
\text { OR }(95 \% \mathrm{Cl})\end{array}$ & $\begin{array}{c}\text { Institutional Care } \\
\text { OR }(95 \% \mathrm{Cl})\end{array}$ \\
\hline \multicolumn{3}{|l|}{ race } \\
\hline white & 1 & 1 \\
\hline black & $1.04(0.93-1.16)$ & $1.27(1.14-1.40)$ \\
\hline Hispanic & $0.84(0.72-0.97)$ & $0.98(0.87-1.09)$ \\
\hline API & $1.34(1.13-1.59)$ & $1.17(0.99-1.37)$ \\
\hline Native American/other & $1.10(0.90-1.34)$ & $1.16(0.98-1.38)$ \\
\hline age & $1.04(1.03-1.04)$ & $1.03(1.02-1.03)$ \\
\hline female sex & $1.19(1.11-1.27)$ & $1.21(1.14-1.28)$ \\
\hline \multicolumn{3}{|l|}{ median income } \\
\hline Q1 (lowest) & 1 & 1 \\
\hline Q2 & $1.02(0.93-1.12)$ & $0.99(0.90-1.08)$ \\
\hline Q3 & $0.87(0.79-0.97)$ & $0.89(0.81-0.98)$ \\
\hline Q4 & $0.79(0.70-0.90)$ & $0.88(0.74-1.06)$ \\
\hline \multicolumn{3}{|l|}{ insurance status } \\
\hline Medicare & 1 & 1 \\
\hline Medicaid & $0.95(0.83-1.09)$ & $0.83(0.75-0.93)$ \\
\hline private/HMO & $0.64(0.58-0.70)$ & $0.65(0.60-0.71)$ \\
\hline self-pay & $1.03(0.90-1.19)$ & $0.54(0.47-0.62)$ \\
\hline no charges & $0.75(0.62-0.90)$ & $0.48(0.41-0.56)$ \\
\hline \multicolumn{3}{|l|}{ admission type } \\
\hline emergency & 1 & 1 \\
\hline urgent & $0.72(0.65-0.82)$ & $1.02(0.91-1.14)$ \\
\hline elective & $0.57(0.49-0.67)$ & $0.80(0.70-0.91)$ \\
\hline \multicolumn{3}{|l|}{ bed size } \\
\hline small & 1 & 1 \\
\hline medium & $0.89(0.67-1.18)$ & $0.87(0.69-1.09)$ \\
\hline large & $0.72(0.55-0.94)$ & $0.72(0.58-0.89)$ \\
\hline \multicolumn{3}{|l|}{ teaching hospital } \\
\hline no & 1 & 1 \\
\hline yes & $0.60(0.53-0.67)$ & $0.64(0.56-0.72)$ \\
\hline \multicolumn{3}{|l|}{ region } \\
\hline Northeast & 1 & 1 \\
\hline Midwest & $0.76(0.64-0.91)$ & $0.85(0.72-0.99)$ \\
\hline South & $0.72(0.61-0.83)$ & $0.63(0.52-0.78)$ \\
\hline West & $0.78(0.65-0.94)$ & $0.72(0.61-0.86)$ \\
\hline \multicolumn{3}{|l|}{$\mathrm{CCl}$ score } \\
\hline 1 & 1 & 1 \\
\hline 2 & $1.21(1.12-1.31)$ & $1.31(1.21-1.41)$ \\
\hline 3 & $1.90(1.67-2.17)$ & $2.84(2.51-3.21)$ \\
\hline$\geq 4$ & $2.23(1.93-2.58)$ & $2.59(2.26-2.97)$ \\
\hline
\end{tabular}

* Estimates presented as multinomial odds ratios with $95 \%$ confidence interval.

American patients were at higher risk of death (OR 1.10, 95\% CI 0.90-1.34) and institutional care (OR 1.16, 95\% CI 0.98-1.38), although the differences were not statistically significant (Table 2). Figure 1 shows a plot of racial/ ethnic differences in the risk of in-hospital mortality by

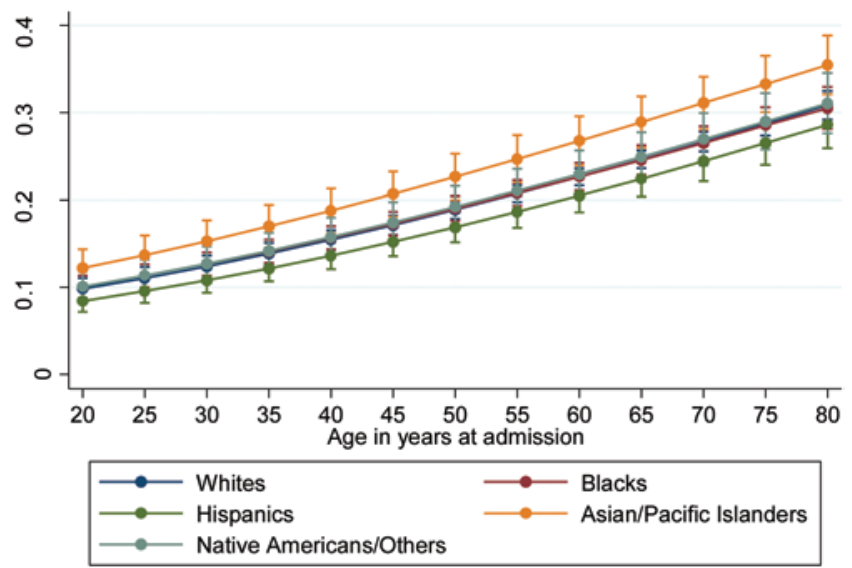

Fig. 1. Plot of racial/ethnic differences in the risk of inpatient mortality by age, expressed as predicted probabilities (y axis). The uppermost curve represents API patients and the lowermost represents Hispanic patients; the other racial/ethnic groups are clustered in the middle.

age, expressed as predicted probabilities. Hispanic patients were the least likely to die during hospitalization, whereas API patients were the most likely to die during hospitalization for SAH.

\section{Discussion}

Among patients with SAH admitted to acute-care hospitals in the US, race/ethnicity was a significant predictor of inpatient mortality and discharge to institutional care. Racial/ethnic differences were present after accounting for age, sex, socioeconomic and insurance status, and other clinical and hospital characteristics that could potentially influence outcomes. The results of this study agree to some extent with those of a study of the New York SPARC (Statewide Planning and Research Cooperative System) database that suggested that white patients with SAH had better functional outcomes than nonwhite patients. ${ }^{30}$ Our findings, however, are different from those of other hospital- ${ }^{15,21,23}$ and population-based studies $^{9,29}$ in the US US,15,21,23 and other countries $^{29}$ that demonstrated no racial/ethnic differences in case fatality rate, ${ }^{15,21}$ functional disability, ${ }^{21}$ or other outcomes. ${ }^{9,29}$ The small number of events observed in previous studies, ${ }^{21}$ especially with respect to groups other than "Whites" or "Blacks,",23,29 may well have contributed to the negative findings of these studies. It is also plausible that differences in the categorization of race/ethnicity in the different studies contributed to the inconsistency between our findings and those of prior studies.

Our analysis showed that black and white patients had a similar risk of death. Previous studies also showed that, after adjustment for important determinants of outcome, these groups do not differ significantly in survival rates, case fatality rate,,$^{15}$ time to treatment, ${ }^{9}$ or 3 -month functional outcome. ${ }^{23}$ Taken together, these findings indicate that black and white patients have a comparable short-term prognosis after SAH. Although in the present study black patients were more likely to be discharged to other facilities rather than to home, whether this result indicates greater residual disability in black patients or is due to the presence of other factors related to referral 


\section{Racial/ethnic differences in mortality rates in patients with SAH}

to or receipt of postacute institutional care can only be a matter of speculation.

Our finding of significantly lower risk of in-hospital mortality in patients of Hispanic ethnicity compared with non-Hispanic white patients agrees with a growing body of epidemiological literature in the US; this literature shows that Hispanic ethnicity is associated with lower risk of all-cause and disease-specific death. ${ }^{3,5,13,17,28}$ The estimated relative risk reduction of $16 \%$ in this study is comparable to the $7 \%-13 \%$ reported for stroke patients of Hispanic ethnicity in the population-based Brain Attack Surveillance in the Corpus Christi Project in Texas. ${ }^{17}$ In the Northern Manhattan Study (NOMAS), ${ }^{28}$ Hispanic ethnicity was associated with much greater risk reduction for coronary death (64\%) and vascular death (34\%). Hispanic populations in the US on average have a lower socioeconomic status, greater burden of risk factors, lower insurance coverage, and lower access to the processes of care than do non-Hispanic white patients. ${ }^{19}$ By experiencing more favorable mortality outcomes than non-Hispanic white patients, Hispanic patients present an "epidemiologic paradox," the cause of which, although the subject of ongoing investigations, remains uncertain. ${ }^{3,28}$

Of the racial/ethnic groups compared in this study, API patients had the highest risk of death and need for postacute institutional care. A somewhat different result was reported by a similar study that used only the 1997 NIS data and found that API patients were similar to nonHispanic white patients in the risk of in-hospital mortality but had more need for postacute institutional care than did non-Hispanic white patients. However, among patients who received thrombolysis for acute ischemic stroke in the US, API patients had the highest risk of death and intracerebral hemorrhage. ${ }^{2,20}$

The prospective, population-based Auckland Regional Community Stroke III study in New Zealand also found that API patients had the worst 6-month functional outcomes after acute ischemic stroke compared with other racial/ethnic groups..$^{18}$ A number of reasons may explain the worse prognosis in API patients. It is possible these patients have more severe SAH. Secondly, some studies have reported that API patients have a relatively low likelihood of admission to high-quality hospitals after stroke, compared with other racial/ethnic groups in the US. ${ }^{25}$ Timely, quality, specialized care has been identified as critical to improved outcomes after SAH. ${ }^{26}$ Furthermore, researchers have reported cultural, language, and other barriers among Asian Americans that could have a significant impact on their capacity to access health care and experience favorable health outcomes. ${ }^{22}$ Nevertheless, these explanations do not account for the fact that API patients in the US constitute a heterogeneous group reflecting to a larger extent than other racial/ethnic groups both extremes of socioeconomic status. For instance, API patients in the present study lived in wealthier neighborhoods relative to other racial/ethnic groups.

\section{Study Limitations}

This study has a number of limitations that could impact its conclusions. First, because the study is not population based, the results do not apply to the $15 \%$ or so of patients with SAH who do not survive to receive treatment in acute-care hospitals. Second, because of its cross-sectional design, the findings should be interpreted with caution for long-term mortality and morbidity outcomes. Third, the categorization of race/ethnicity, as it is done in the NIS, is a social construct that is not based on any unique genetic composition; hence, the results of this study may not necessarily be due to genetic differences among studied groups. Fourth, because the NIS has no variable to measure SAH severity, we did not adjust for this important prognostic factor and hence could not ascertain whether controlling for SAH severity could have attenuated the observed racial/ethnic differences. Last, because some states do not submit information on race to the NIS, this information was missing for $20 \%$ of discharges and we resorted to multiple imputation to minimize loss of data points.

Although this approach is considered better than a complete case analysis, it does not completely eliminate the inherent bias due to missing data on race. ${ }^{11}$ Despite these limitations, this study used a very large sample size, far exceeding those of any previous studies, which makes any insignificant results not due to a lack of statistical power. The nationwide data also enhance the generalizability of the results. Furthermore, the findings are more applicable to a contemporary context because the cohort is more reflective of current treatment practices in SAH than were the cohorts in previous studies.

\section{Conclusions}

This study found that patients with SAH who survived to receive treatment in hospitals differed significantly in their risk of in-hospital mortality and use of institutional postacute care when compared according to their self-reported racial/ethnic groups. The study indicated Hispanic patients have the best outcomes and that API patients have the worst outcomes during the inpatient course. The reasons for these prognostic disparities deserve further research because they appear to be important in improving outcomes in identified high-risk groups.

\section{Acknowledgment}

We would like to express our gratitude to Professor Muhammed Mamdani for reading and making useful comments to improve the manuscript.

\section{Disclosure}

Dr. Saposnik is supported by the Distinguished Clinician Scientist Award from Heart \& Stroke Foundation of Canada (HSFC). $\mathrm{He}$ also serves on the editorial boards of Stroke, the Journal of Stroke and Cerebrovascular Disease, and International Journal of Stroke. Dr. Macdonald discloses the following: ownership in Edge Therapeutics, Inc.; grant support from Brain Aneurysm Foundation, Physicians Services Incorporated Foundation, HSFC, and Canadian Institutes of Health Research; and consultant activities for Actelion Pharmaceuticals. This research was not funded by a grant. The authors have no conflict of interest with regard to the methods or materials used in the study or the reported findings.

Author contributions to the study and manuscript preparation include the following. Conception and design: Macdonald, 
Jaja, Saposnik, Schweizer. Acquisition of data: Macdonald, Jaja. Analysis and interpretation of data: Jaja, Nisenbaum, Lo, Thorpe. Drafting the article: Jaja. Critically revising the article: all authors. Reviewed submitted version of manuscript: all authors. Approved the final version of the manuscript on behalf of all authors: Macdonald. Statistical analysis: Jaja, Nisenbaum, Lo, Thorpe. Administrative/technical/material support: Jaja. Study supervision: Macdonald, Saposnik, Thorpe.

\section{References}

1. Ayala C, Greenlund KJ, Croft JB, Keenan NL, Donehoo RS, Giles WH, et al: Racial/ethnic disparities in mortality by stroke subtype in the United States, 1995-1998. Am J Epidemiol 154:1057-1063, 2001

2. Bateman BT, Schumacher HC, Boden-Albala B, Berman MF, Mohr JP, Sacco RL, et al: Factors associated with in-hospital mortality after administration of thrombolysis in acute ischemic stroke patients: an analysis of the nationwide inpatient sample 1999 to 2002. Stroke 37:440-446, 2006

3. Borrell LN, Lancet EA: Race/ethnicity and all-cause mortality in US adults: revisiting the Hispanic paradox. Am J Public Health 102:836-843, 2012

4. Broderick JP, Brott T, Tomsick T, Huster G, Miller R: The risk of subarachnoid and intracerebral hemorrhages in blacks as compared with whites. N Engl J Med 326:733-736, 1992

5. Brown HL, Chireau MV, Jallah Y, Howard D: The "Hispanic paradox": an investigation of racial disparity in pregnancy outcomes at a tertiary care medical center. Am J Obstet Gynecol 197:e1-e9, 2007

6. Bruno A, Carter S, Qualls C, Nolte KB: Incidence of spontaneous subarachnoid hemorrhage among Hispanics and nonHispanic whites in New Mexico. Ethn Dis 7:27-33, 1997

7. Deyo RA, Cherkin DC, Ciol MA: Adapting a clinical comorbidity index for use with ICD-9-CM administrative databases. J Clin Epidemiol 45:613-619, 1992

8. Eden SV, Meurer WJ, Sánchez BN, Lisabeth LD, Smith MA, Brown DL, et al: Gender and ethnic differences in subarachnoid hemorrhage. Neurology 71:731-735, 2008

9. Eden SV, Morgenstern LB, Sekar P, Moomaw CJ, Haverbusch M, Flaherty ML, et al: The role of race in time to treatment after subarachnoid hemorrhage. Neurosurgery 60:837-843, 2007

10. Ferro JM, Canhão $P$, Peralta R: Update on subarachnoid haemorrhage. J Neurol 255:465-479, 2008

11. Groenwold RH, Donders AR, Roes KC, Harrell FE Jr, Moons KG: Dealing with missing outcome data in randomized trials and observational studies. Am J Epidemiol 175:210-217, 2012

12. Hoh BL, Rabinov JD, Pryor JC, Carter BS, Barker FG II: Inhospital morbidity and mortality after endovascular treatment of unruptured intracranial aneurysms in the United States, 1996-2000: effect of hospital and physician volume. AJNR Am J Neuroradiol 24:1409-1420, 2003

13. Hummer RA, Powers DA, Pullum SG, Gossman GL, Frisbie WP: Paradox found (again): infant mortality among the Mexican-origin population in the United States. Demography 44: 441-457, 2007

14. Kennedy BS, Kasl SV, Brass LM, Vaccarino V: Trends in hospitalized stroke for blacks and whites in the United States, 1980-1999. Neuroepidemiology 21:131-141, 2002

15. Kissela B, Schneider A, Kleindorfer D, Khoury J, Miller R, Alwell K, et al: Stroke in a biracial population: the excess burden of stroke among blacks. Stroke 35:426-431, 2004
16. Labovitz DL, Halim AX, Brent B, Boden-Albala B, Hauser WA, Sacco RL: Subarachnoid hemorrhage incidence among Whites, Blacks and Caribbean Hispanics: the Northern Manhattan Study. Neuroepidemiology 26:147-150, 2006

17. Lisabeth LD, Risser JM, Brown DL, Al-Senani F, Uchino K, Smith MA, et al: Stroke burden in Mexican Americans: the impact of mortality following stroke. Ann Epidemiol 16:33-40, 2006

18. McNaughton H, Feigin V, Kerse N, Barber PA, Weatherall $\mathrm{M}$, Bennett D, et al: Ethnicity and functional outcome after stroke. Stroke 42:960-964, 2011

19. Morales LS, Lara M, Kington RS, Valdez RO, Escarce JJ: Socioeconomic, cultural, and behavioral factors affecting Hispanic health outcomes. J Health Care Poor Underserved 13: 477-503, 2002

20. Nasr DM, Brinjikji W, Cloft HJ, Rabinstein AA: Racial and ethnic disparities in the use of intravenous recombinant tissue plasminogen activator and outcomes for acute ischemic stroke. J Stroke Cerebrovasc Dis 22:154-160, 2013

21. Nguyen-Huynh MN, Johnston SC: Regional variation in hospitalization for stroke among Asians/Pacific Islanders in the United States: a nationwide retrospective cohort study. BMC Neurol 5:21, 2005

22. Paek MS, Lim JW: Factors associated with health care access and outcome. Soc Work Health Care 51:506-530, 2012

23. Rosen D, Novakovic R, Goldenberg FD, Huo D, Baldwin ME, Frank JI, et al: Racial differences in demographics, acute complications, and outcomes in patients with subarachnoid hemorrhage: a large patient series. J Neurosurg 103:18-24, 2005

24. Schievink WI, Riedinger M, Jhutty TK, Simon P: Racial disparities in subarachnoid hemorrhage mortality: Los Angeles County, California, 1985-1998. Neuroepidemiology 23:299305,2004

25. Shen JJ, Lu M: Changes in patterns of racial disparities in attending low-mortality hospitals and outcomes among patients with stroke. Ethn Dis 21:135-141, 2011

26. Vespa P, Diringer MN: High-volume centers. Neurocrit Care 15:369-372, 2011

27. White IR, Royston P, Wood AM: Multiple imputation using chained equations: issues and guidance for practice. Stat Med 30:377-399, 2011

28. Willey JZ, Rodriguez CJ, Moon YP, Paik MC, Di Tullio MR, Homma $S$, et al: Coronary death and myocardial infarction among Hispanics in the Northern Manhattan Study: exploring the Hispanic paradox. Ann Epidemiol 22:303-309, 2012

29. Wolfe CD, Rudd AG, Howard R, Coshall C, Stewart J, Lawrence $\mathrm{E}$, et al: Incidence and case fatality rates of stroke subtypes in a multiethnic population: the South London Stroke Register. J Neurol Neurosurg Psychiatry 72:211-216, 2002

30. Zacharia BE, Grobelny BT, Komotar RJ, Connolly ES, Mocco $\mathrm{J}$ : The influence of race on outcome following subarachnoid hemorrhage. J Clin Neurosci 17:34-37, 2010

Manuscript submitted March 19, 2013

Accepted July 25, 2013.

Please include this information when citing this paper: published online September 10, 2013; DOI: 10.3171/2013.7.JNS13544.

Address correspondence to: R. Loch Macdonald, M.D., Ph.D., F.R.C.S., Division of Neurosurgery, St. Michael's Hospital, University of Toronto, 30 Bond St., Toronto, ON, Canada M5B 1W8. email: macdonaldlo@smh.ca. 